10.1590/S1414-40772018000300011

Este é um artigo publicado em acesso aberto sob uma licença Creative Commons

https://creativecommons.org/licenses/by-nc/4.0/

\title{
A formação de um arquiteto social e ético: dilemas das universidades brasileiras
}

\author{
Cláudio Lima Ferreira ${ }^{1}$ \\ Wilson Flório²
}

Resumo: O artigo tem como objetivo apresentar e discutir a formação social e ética do arquiteto, a partir do pensar reflexivo no ensino de Arquitetura e Urbanismo no Brasil ${ }^{1}$. A universidade tem se limitado a ser um órgão de repetição e de difusão do saber elaborado em outros locais com diferentes realidades, e que muito pouco tem contribuído para uma integração nacional, consequência de uma análise crítica da nossa realidade. O profissional Arquiteto e Urbanista da atualidade precisa repensar sua atuação na sociedade, tendo especial atenção às questões humanísticas e sustentáveis, com vistas a proporcionar a melhoria da qualidade de vida dos seres humanos. Dessa forma, entender as formas de aprendizagem por meio de um ensino prático-reflexivo, é de suma importância para o desenvolvimento do ensino de Arquitetura e Urbanismo no Brasil. A pesquisa de caráter exploratório bibliográfica visa analisar os estudos que se propõem a auxiliar os docentes e discentes em adquirirem aptidões essenciais para atingir competências em zonas indeterminadas da prática. Algumas tentativas de discussão sobre o ensino e a constituição de uma verdadeira universidade no Brasil foram abordadas nesse artigo, por meio de análises de documentos e entrevistas como a Conferência Episcopal Latino-Americana CELAM e a Carta para a Educação dos Arquitetos- UNESCO/UIA. Conclui-se que as Instituições de Ensino Superior brasileiras devem reestruturar a sua forma de ensinar Arquitetura e Urbanismo; visando a formação de profissionais reflexivos, criativos e colaborativos, uma vez que estas contribuirão efetivamente para a consolidação da formação social e ética do Arquiteto e Urbanista no Brasil.

Palavras-chave: Ensino de arquitetura. Formação reflexiva. Arquitetura ética e social.

\section{The social and ethic formation of the architect: dilemmas of brazilian universities}

Abstract: This article aims to present and discuss the social and ethic formation of the architect, from the reflective thinking in the teaching of Architecture and Urbanism in Brazil. The university has been limited to a repeat of organ and diffusion of knowledge developed in other places with different realities, and that very little has contributed to national integration, the result of a critical analysis of our reality. Professional Architect and Urban Planner of today need to rethink their role in society, with special attention to humanistic and sustainable issues, with a view to providing a better quality of life of human beings. Thus, understanding the ways of learning through a hands-reflective teaching, it is of paramount importance for the development of Architecture and Urbanism of education in Brazil. The literature exploratory research aims to analyze the studies that purport to assist teachers and students in acquiring essential skills to achieve skills in indeterminate areas of practice. Some attempts to discussion about teaching and the creation of a real university in Brazil forarm addressed in this article, through document reviews and interviews as the Latin American Episcopal Conference CELAM and the Charter for Education Arquitetos - UNESCO / UIA. It concludes that the Brazilian Higher Education Institutions must restructure its way of teaching Architecture and Urbanism; aiming at the formation of reflective, creative and collaborative professionals, as these contribute effectively to the consolidation of the social and ethic formation of the urbanist architect in Brazil.

Key words: Architecture education. Reflective training. Social architecture.

\footnotetext{
${ }^{1}$ Este artigo tem como base a pesquisa de pós-doutorado intitulada: Formando Profissionais reflexivos, criativos e colaborativos: o ensino de Arquitetura e Urbanismo no Brasil, desenvolvida na Universidade Presbiteriana Mackenzie pelo Dr. Cláudio Lima Ferreira e supervisionada pelo Dr. Wilson Flório (2014).
} 


\section{Introdução}

Nos últimos anos, o ensino de Arquitetura e Urbanismo no Brasil está sofrendo contínuas alterações influenciadas por diversos fatores, sejam pelas leis do Ministério da Educação Brasileiro, pelas resoluções do Conselho de Arquitetura e Urbanismo no Brasil, pelas peculiaridades das Instituições de Ensino Superior públicas ou privadas, ou pelo atual mercado profissional cada vez mais globalizado e competitivo. Esses fatores, direta ou indiretamente, influenciam e direcionam a reorganização do ensino no país, visando a contínua estruturação das matrizes curriculares, dos conteúdos programáticos e das novas metodologias de ensino e aprendizagem. É importante salientar que os estudos sobre a formação/deformação do ensino/aprendizagem das atuais profissões no Brasil devem ser incessantemente produzidos e discutidos pois a universidade, de forma geral, se volta para parâmetros internacionais que acabam impactando na pesquisa dos docentes e por sua vez no ensino que em muitas vezes encontram-se descolados da realidade.

A partir dessas abordagens, verifica-se que é de suma importância para o desenvolvimento do ensino de Arquitetura e Urbanismo no Brasil compreender as atuais teorias educacionais, sobretudo novas estratégias instrucionais, visando consolidar a atuação do arquiteto e urbanista na sociedade brasileira. Atualmente existe uma grande preocupação em evidenciar e acima de tudo formar profissionais arquitetos e urbanistas com uma visão para a melhoria da qualidade de vida dos seres humanos, repensando sua atuação sobre a sociedade como um todo, principalmente sobre questões humanísticas e sustentáveis. Dessa forma, entender as formas de aprendizagem por meio de um ensino prático-reflexivo, é fundamental para o desenvolvimento do ensino de Arquitetura e Urbanismo no Brasil.

O que esperamos do ensino de Arquitetura e Urbanismo no Brasil? Qual a importância de formarmos profissionais com compromissos sociais e éticos? Como ensinar Arquitetura e Urbanismo com os avanços das tecnologias comunicacionais e informacionais? Qual a necessidade de formarmos profissionais reflexivos, criativos e colaborativos?

$\mathrm{Na}$ tentativa de contribuir com o debate, este artigo tem como objetivo apresentar e discutir a formação social e ética do arquiteto, a partir do pensar reflexivo no ensino de Arquitetura e Urbanismo no Brasil. Destacando também, a importância de questionar sobre qual profissional queremos para o futuro e instigar novas pesquisas sobre o ensino de arquitetura e urbanismo no Brasil.

Vale ressaltar que o artigo não tem a pretensão de cobrir toda a amplitude do debate, e tampouco de abranger todas as especificidades sobre o ensino/aprendizagem dos cursos de 
Arquitetura e Urbanismo no Brasil. Pretende-se apenas apresentar um panorama das reflexões conduzidas por alguns autores sobre a importância da formação reflexivos, criativos e colaborativos com visão social e ética.

Para cumprir esse desafio, o artigo está dividido em duas sessões, além desta introdução. Na primeira são apresentados e discutidos os aspectos fundamentais do ensino superior no Brasil, enfatizando a nova forma de ensinar e aprender, visando a reflexão e a colaboração dentro de uma sociedade que vivencia os constantes avanços da sociedade. A segunda sessão apresenta o debate sobre o que esperamos do ensino de arquitetura e urbanismo no Brasil a partir da Carta para a Educação dos Arquitetos - UNESCO/UIA. Por fim, são apresentadas algumas considerações finais baseadas nas reflexões geradas ao longo do trabalho.

\section{O ensino superior no Brasil}

Ser reflexivo, criativo e colaborativo instiga dúvidas, contestações, indignações, inquietações que por muitos docentes, pesquisadores, políticos e empresários antiquados é visto como negativo. Essa análise acende uma calorosa discussão que teve início em 1984 com o lançamento do livro Homo Academicus por Pierre Bourdieu (1984).

Nesse livro o autor analisa, a partir de considerações sobre o campo universitário francês, o sistema universitário do ponto de vista do poder simbólico que possui e da violência simbólica que exerce. Trata-se de uma crítica ao campo acadêmico, entretanto embasada por abordagens explicativas que fornecem limites à crítica pela crítica, e impõe a força de uma crítica apoiada na metodologia e na visão sociológica que conhece os limites da "força intrínseca da ideia verdadeira".

No segundo capítulo intitulado "O conflito das faculdades", Bourdieu (1984) coloca que a posição ocupada em um campo está ligada ao capital cultural. O conflito das Instituições de Ensino Superior- IES se estabelece pelo "monopólio do pensamento e do discurso legítimo sobre o mundo social", fundamentados em uma mesma "ciência da ordem e do poder", onde os professores visam à racionalização da ordem estabelecida e, de outro, não pretendem ordenar as coisas públicas, e sim "pensá-las como tais, pensar o que é a ordem social".

O autor coloca os enormes obstáculos que alguns devem passar para transformar a ordem dominante, bem como as dificuldades para sobreviver em uma luta que é de "todos 
contra todos", e na qual os agentes são interdependentes e, ao mesmo tempo, concorrentes e clientes, adversários e juízes para determinar sua verdade e seu valor.

A grande questão nesse livro é compreender que o mundo acadêmico que é o lugar da discussão, do debate e do diálogo, também é o lugar de disputas de poder, presas em seus micro espaços de pesquisa e atuação. Boudieu em seu livro Homo Academicus agita as estruturas do campo científico e retira os docentes e pesquisadores de seu local de conforto; obrigando a todos repensarem suas crenças e seus objetivos acadêmicos.

Dentro de Instituições de Ensino tradicionais, muitas vezes impera um modo muito hierárquico das decisões, compartimentadas em várias instâncias de poder, que centralizam ações, e paralisam a iniciativa de boas práticas pedagógicas. Neste tipo de relação, prioriza-se profissionais obedientes, passivos, e que cumpram suas atividades sem questionar o habitus vigente. Este tipo de pensamento pode ser bom e válido para muitos profissionais que preferem se manter descompromissados com o desenvolvimento de um país e de uma sociedade melhor e mais justa, entretanto, para muitos profissionais e futuros profissionais, este não é o ideal de vida. Isso pode ser confirmado com as últimas manifestações que ocorreram no Brasil no ano de 2013, mostrando que o povo brasileiro é reflexivo, questionador e contestador.

Não se tem como objetivo julgar as escolhas, mesmo porque se deve respeitar as diferentes opiniões e sabe-se que é através dessas diferenças que a humanidade se desenvolve. Na realidade, uma sociedade sem diferenças é uma sociedade sem informação.

Possibilitar a formação de profissionais reflexivos, criativos e colaborativos é de suma importância para que tenham compromissos com desenvolvimento social e ético no Brasil, contudo, para que isso seja verdadeiramente aplicado, é preciso uma reestruturação na forma de ensinar e de aprender. Esta nova forma de ensinar e aprender, visando a reflexão e a colaboração dentro de uma sociedade que vivencia os constantes avanços das tecnologias comunicacionais e informacionais, deve ser entendida, como uma necessidade de mudança a curto e médio prazo.

Estas mudanças devem ser encaradas de modo positivo, por discentes e docentes, na forma de aprender/ ensinar e, principalmente pelos gestores institucionais na forma de gerir e de direcionar esta nova forma de ensino/aprendizagem dentro do Plano de Desenvolvimento Institucional, do Projeto Pedagógico Institucional e do Projeto Pedagógico de Curso, envolvendo, assim as diversas instâncias institucionais focadas na formação de profissionais reflexivo, criativos e colaborativo. 
A mudança não pode vir apenas de um lado, mas sim do afinamento de todos os atores pertencentes à Instituição de Ensino Superior, com a finalidade de retomar o verdadeiro objetivo da Universidade ${ }^{2}$, que é universalizar o conhecimento.

O que esperamos do ensino de Arquitetura e Urbanismo no Brasil? Qual a importância de formarmos profissionais com compromissos sociais e éticos? Como ensinar Arquitetura e Urbanismo com os avanços das tecnologias comunicacionais e informacionais? Qual a necessidade de formarmos profissionais reflexivos, criativos e colaborativos? Este artigo tem a função de questionar sobre qual profissional queremos para o futuro e instigar novas pesquisas sobre o ensino de arquitetura e urbanismo no Brasil.

Para Luckesi et al. (2001), diante de um sistema educacional, como um todo, e da universidade em particular, propõe-se a nossa reflexão na busca de entender a realidade atual da nossa universidade. Nesse sentido, busca-se construir a universidade que, seja construtora de novos conhecimentos, e não uma mera reprodutora de informações importadas para "profissionalizar" novos quadros. Deste modo a universidade assume um papel como protagonista do repensar a sociedade, torna-se um local privilegiado onde seja cultivado, a reflexão e a crítica sobre a realidade, gerando assim, conhecimentos válidos, amparados em bases científicas.

Nesse sentido, se analisarmos a Lei 5.540-68 da reforma universitária com referência ao ensino superior, verifica-se que:

\begin{abstract}
Art. $1^{\circ}$ - $\mathrm{O}$ ensino superior tem por objetivo a pesquisa, o desenvolvimento das ciências, letras e artes e a formação de profissionais de nível universitário.

Art. $2^{\circ}-\mathrm{O}$ ensino superior indissociável da pesquisa será ministrado em universidades e, excepcionalmente, em estabelecimentos isolados, organizados como instituições de direito público ou privado.
\end{abstract}

De fato, como bem apontou Luckesi et al. (2001), no Brasil, mais do que nos países latino-americanos colonizados pelos espanhóis, o processo de transplante cultural, ligado sempre aos interesses do colonizador, condicionou as funções da universidade existentes. Durante um bom período se importou técnicas e recursos culturais sem uma reflexão mais aguda. Nesses termos, Anísio Teixeira (1969, p. 46) dizia que na:

\footnotetext{
2 Mesmo sabendo das diferenças formais e legais no Brasil entre Universidade, Centros Universitários e Faculdades, nesse artigo faz-se necessário defini-las apenas como Instituições de Ensino Superior que possuem como características desejáveis a universalização do conhecimento. Entretanto em alguns momentos palavra Universidade foi a melhor definição para a discussão sobre a universalização do conhecimento nas Instituições de Ensino Superior. A palavra Universidade vem do Latim Universitas e significa - universalidade, o todo, o Universo.
} 
Universidade brasileira, além de preparar profissionais para as carreiras liberais e técnicas que exigem uma formação de nível superior, o que tem havido é uma preocupação muito fluida com a iniciação do estudante na vida intelectual. Daí poder-se afirmar que, ressalvando o aspecto habilitação profissional, a universidade brasileira não logrou constituir-se verdadeiramente como uma instituição de pesquisa e transmissora de uma cultura comum nacional, nem logrou se tornar um centro de consciência crítica e de pensamento criador.

Com relação a posição dos intelectuais numa sociedade em mudança, Florestan Fernandes (1976, p. 87) assim escreveu:

A polêmica entre os que defendem o "intelectual participante e os que postulam a "neutralidade da inteligência funda-se, sociologicamente considerada, num falso dilema. Não existe inteligência "neutra" nem poderia eximir qualquer produção cultural do homem de algum estado de "participação".

As Instituições de Ensino Superior e, sobretudo seus professores, não podem se eximir da corresponsabilidade de construir os saberes necessários para os avanços sociais, assim como não podem ser meros espectadores de correntes de pensamento advindas de outras culturas, que muitas vezes são totalmente artificiais em nosso contexto sociocultural.

Nessa mesma linha de pensamento, pode-se também destacar o alerta feito por Roland Corbisier (1960, p. 53) no ISEB $^{3}$ em 1960:

Colonizado mentalmente, o intelectual brasileiro assim como utilizava, sem transformá-los, os produtos acabados da indústria estrangeira, assim também pensava, sem transformá-las, com as ideias prontas que lhe vinham de fora [...] Perdido nos "outros", sua cultura se reduzia à erudição, quer dizer, ao conhecimento livresco das culturas alheias.

Nota-se a validade desta afirmação até os tempos presentes, nos conteúdos de disciplinas que nada modificaram esta situação. Sem a devida reflexão própria, sem ser capaz de interpretar sua própria história e suas reais necessidades, professores adotam ingenuamente conhecimentos que não se aplicam à nossa realidade, nem tampouco às diferentes realidades presentes num país continental como é o Brasil.

Outro pensador do Brasil, Darcy Ribeiro (1975), também constatou, que a universidade tem se limitado a ser um órgão de repetição e de difusão do saber elaborado em outras realidades, e que muito pouco tem contribuído para uma integração nacional, consequência de uma análise crítica da nossa realidade.

Em sintonia com os pensadores mencionados anteriormente, Luckesi et al. (2001) ressalta que as funções da Universidade existente no Brasil, mesmo após a dita independência política, continuam a ser de absorção, aplicação e difusão do saber humano, fruto da atividade

\footnotetext{
${ }^{3}$ Em julho de 1955, foi criado o Instituto Superior de Estudos Brasileiros (ISEB), órgão do MEC dotado de autonomia administrativa e de liberdade de pesquisa, de opinião e de cátedra, destinado ao estudo, ao ensino e à divulgação das ciências sociais. Corbusier foi escolhido para o cargo de diretor-executivo. Iniciando suas atividades no momento em que Juscelino Kubitschek assumia a presidência da República (1956-1961)
} 
intelectual dos grandes centros técnico-científicos das nações desenvolvidas. Nossas escolas universitárias, quando muito, mantêm sua clientela informada dos resultados das investigações feitas sobre problemas de outras realidades, e não daqueles emergentes das necessidades e desafios de nossa nação e de nosso povo.

De acordo com Luckesi et al. (2001, p. 33)

A universidade que não toma a si esta tarefa de refletir criticamente e de maneira continuada sobre o momento histórico em que ela vive, sobre o projeto da sua comunidade, não está realizando sua essência, sua característica que a especifica como tal crítica. Isso nos quer dizer que a universidade é por excelência, razão concretizada, inteligência institucionalizada, daí ser por natureza, crítica, porque a razão é eminentemente crítica.

Algumas tentativas de discussão sobre uma verdadeira universidade no Brasil são válidas até hoje. Pode-se constatar essa tentativa na Conferência Episcopal Latino-Americana - CELAM (1978, p. 16), que ocorreu há mais de quarenta e cinco anos e que colocou:

Estamos com uma educação uniforme em um momento em que a comunidade latino-americana despertou para a riqueza de seu pluralismo humano; passiva, quando já soou à hora para nossos povos de descobrirem seu próprio ser, pleno de originalidade; está orientada no sentido de sustentar uma economia baseada na ânsia do 'ter mais', quando a juventude latino-americana exige 'ser mais', na posse de sua autorrealização pelo serviço e no amor. Em especial a formação de nível médio e superior sacrifica com frequência a profundidade humana em nome do pragmatismo e do imediatismo para ajustar-se às exigências do mercado de trabalho. Este tipo de educação é responsável pela colocação do homem a serviço da economia e não desta a serviço do homem.

Analisar e compreender estas tentativas de discussão sobre a verdadeira universidade no Brasil, que ocorre há muito tempo, é fundamental para questionar o que se quer do futuro da nossa educação e, sobretudo, entender a relação entre lucro e educação na contemporaneidade.

Recentemente o Papa Francisco (2013, p. 3) em visita ao Brasil questionou em uma entrevista sobre a relação entre lucro e educação:

Queria dizer-lhes também que a Igreja, 'advogada da justiça e defensora dos pobres diante das intoleráveis desigualdades sociais e econômicas, que clamam ao céu' (Documento de Aparecida, 395), deseja oferecer a sua colaboração em todas as iniciativas que signifiquem um autêntico desenvolvimento do homem todo e de todo o homem. Queridos amigos, certamente é necessário dar o pão a quem tem fome; é um ato de justiça. Mas existe também uma fome mais profunda, a fome de uma felicidade que só Deus pode saciar. Não existe verdadeira promoção do bem-comum, nem verdadeiro desenvolvimento do homem, quando se ignoram os pilares fundamentais que sustentam uma nação, os seus bens imateriais: a vida, que é dom de Deus, um valor que deve ser sempre tutelado e promovido; a família, fundamento da convivência e remédio contra a desagregação social; a educação integral, que não se reduz a uma simples transmissão de informações com o fim de gerar lucro; a saúde, que deve buscar o bem-estar integral da pessoa, incluindo a dimensão espiritual, que é essencial para o equilíbrio humano e uma convivência saudável; a segurança, na convicção de que a violência só pode ser vencida a partir da mudança do coração humano.

Quando o Papa Francisco fala que a educação integral não se reduz a uma simples transmissão de informações com o fim de gerar lucro, todos nós devemos parar e pensar: Qual 
é a educação que queremos? O que algumas Instituições de Ensino Superior, que visam prioritariamente o retorno de lucro, estão pensando do futuro da educação no país? Só queremos profissionais passivos trabalhando para gerar mais lucro para as corporações? A educação é um produto? Será que queremos construir conhecimento ou viver à sombra dos países mais desenvolvidos? Como estimular a pesquisa no nosso país?

É importante salientar que atualmente um dos setores economicamente mais rentável é o setor de educação. Os estudos acerca da mercantilização, mercadorização e capitalismo acadêmico demonstram como o conhecimento e as formações se voltam para a utilidade do mercado, o "grande" interlocutor da universidade, com o imperativo da economia do conhecimento. Para Sguissardi (2005, p. 31):

\begin{abstract}
Um simples olhar panorâmico sobre a expansão quantitativa de instituições privadas, notadamente com fins lucrativos (for profit), e das matrículas nessas instituições, assim como sobre a lenta mas firme redução dos investimentos estatais nas universidades públicas, com relação ao PIB, de uma amostra aleatória de países ricos e pobres, fornecerá provas contundentes de que a universidade e, por extensão, a educação superior estão passando por profundas mudanças, de que esse dilema - público ou privado/mercantil - ocupa lugar central.
\end{abstract}

As atuais reflexões sobre o ensino superior como bem público ou como bem privado, e consequentemente, as discussões envolvendo a contraposição estatal/público versus privado/mercantil encontram-se na luz de um Brasil atormentado pela corrupção e em reestruturação política.

Sguissardi (2005, p. 27) salienta que:

\begin{abstract}
Nesses momentos, o pano de fundo para as campanhas de alfabetização em massa, para a construção de escolas tecnológicas ou politécnicas, para o incentivo a que todos tenham acesso ao máximo de saber e qualificação é a idéia de que o conhecimento, a ciência e a educação não se reduzem a, nem podem ser essencialmente, uma mercadoria ou commodity qualquer (rivalidade e excluibilidade), mas que são fundamentalmente um bem público, coletivo, fruto do trabalho humano solidário ou explorado nas relações de produção capitalistas, um bem que não se desgasta, não se degrada, mas, ao contrário, cresce e multiplica-se pelo uso individual e coletivo e constitui-se em parte essencial dos direitos humanos de cidadania.
\end{abstract}

Nesse sentido é necessário reafirmar que o ensino superior não deve ser definido como uma empresa do saber de formação orientada pelas leis do mercado. Deve-se refletir sobre o futuro do ensino superior no Brasil sobretudo sobre a qualidade do ensino/aprendizagem aplicadas por algumas instituições que se intitulam de "ensino superior".

Entre as diversas discussões sobre as Instituições de Ensino Superior no Brasil Rafael Dias e Milena Serafim (2015, p.43), analisam também algumas das principais transformações pelas quais a universidade brasileira, tem passado ao longo das últimas décadas, com ênfase ao conjunto de três processos que estão conectados pela racionalidade neoliberal: a emergência do capitalismo acadêmico, a gênese do inovacionismo e o acirramento do produtivismo na pesquisa. 
Em um ambiente em que a reflexão, o pensamento crítico, o belo e o lúdico são necessários inclusive para que a missão civilizatória da universidade seja viável - o imperativo produtivista, idealmente, não encontraria terreno fértil para prosperar. Essa, contudo, não é a realidade: a imagem da universidade que temos hoje já não se apresenta tão mais distante daquela de uma hipotética gráfica onde são produzidos materiais impressos e cuja produção, em termos de volume, é até mesmo mais importante que o próprio conteúdo que veicula, ou o efeito social das ideias que dissemina.

Em grande parte das universidades privadas brasileiras verifica-se uma visão empresarial cada vez mais voltada para a produção, para o aluno como cliente e principalmente com foco no retorno financeiro, deixando a qualidade do ensino/aprendizagem apenas como um possível diferencial para a concorrência de mercado. Este foco na produção pode ser notado, por exemplo, na cobrança de produção de artigos pelos docentes/pesquisadores dessas instituições, priorizando a quantidade de artigos produzidos e não a qualidade desses artigos.

Milena Pavan Serafim (2011, p. 65) aborda em sua pesquisa a questão da América Latina e o processo de comoditização da educação superior com ênfase principalmente a mercantilização da educação privada.

Os debates referentes à mudança ocorrida nos sistemas de educação superior latino-americanos abordam, principalmente, a ocorrência e os efeitos de dois processos desencadeados nessa região. O primeiro se refere à tendência mercantilizante e utilitarista da universidade pública, em decorrência - poder-se-ia dizer - daquela ocorrida nos países centrais. O segundo está relacionado ao processo de comoditização da educação privada, enquanto da expansão das universidades privadas. Consequentemente, são esses os temas mais debatidos pela literatura dedicada à educação superior na região.

Sabendo que o processo de mercantilização está enraizado nas bases da educação superior mundial e principalmente brasileira a questão que nos faz refletir, é como fazer um ensino privado de qualidade sendo que o lucro é considerado muito mais importante do que a educação?

Para Serafim (2011, p.44):

Enquanto outros setores da sociedade não se manifestam, o embate dependerá em grande medida da própria academia. Tendo em vista que a universidade não é um bloco monolítico, a esperança é de que grupos de pesquisadores venham a crescer, conjuntamente com a conscientização dos movimentos sociais, e a resistir a esse processo de mercantilização que vem engendrando nas bases da educação superior mundial.

Pode-se verificar que o docente/pesquisador, a partir da formação de seus alunos, tem papel fundamental na reestruturação de uma nova forma de entender a atual mercantilização da educação superior no Brasil. É fundamental que estes docentes estimulem seus alunos em exercícios técnicos, sociais e éticos visando a formação de profissionais, reflexivos, criativos e colaborativos. 
Luckesi et al. (2001, p. 69) constata que queremos produzir conhecimento a partir de uma realidade vivida, e não de critérios estereotipados e pré-definidos por situações culturais diferentes e alheias às que temos aqui agora. Nesse contexto, a validez de qualquer conhecimento será mensurada na proporção em que este possa, ou não, fazer entender melhor e mais profundamente a realidade concreta.

Segundo Ferreira (2016, p. 33) para que tal clima se faça, é obviamente necessário que o docente esteja sempre bem informado da realidade como um todo, e de sua área de especialização em particular, através do estudo e pesquisa, a fim de que possa proporcionar a seus alunos temas de reflexão concretos, problemas e fontes de estudos, proposições criativas e originais, decorrentes da incessante observação crítica da realidade. Ocasionando o desenvolvimento, potencial de reflexão crítica dos alunos, o professor se torna um motivador do saber. Dessa forma, não se trata mais de uma universidade em que um sabe e muitos não, mas sim uma em que muitos sabem algo e querem saber mais. Enfim, desejamos no Brasil uma universidade onde, além de se consumir conhecimento, docentes e discentes optem por criá-lo e produzi-lo.

O CELAM (1978, p. 9) coloca que:

O educando é o primeiro agente do processo educativo, é ele quem se educa a si mesmo; ao educador compete apenas estimular e ordenar inteligentemente esse processo, de maneira que não seja anulada a espontaneidade e criatividade do educando; pelo contrário, deve chegar a expressar em forma autenticamente pessoal o seu conteúdo.

As relações entre educador e educando está sempre em processo de mutação. Deve-se pensar continuamente nesta relação e, principalmente, como a instrução pode contribuir para o desenvolvimento do ensino e da aprendizagem.

Nesse contexto, se abordará abaixo a atuação do arquiteto e urbanista no Brasil e a formação de um profissional reflexivo, criativo e colaborativo visando a consolidação de um profissional com responsabilidades sociais e éticas.

\section{O que esperamos do ensino de arquitetura e urbanismo no Brasil - UNESCO/UIA -}

\section{Carta para a Educação dos Arquitetos.}

A Carta para a Educação dos Arquitetos- UNESCO/UIA foi escrita em 1996 e revisada em 2004 e em 2011, tem como principal objetivo a criação de uma rede global de educação de arquitetos visando o compartilhamento de todas as questões arquitetônicas e urbanísticas.

Segundo a Carta para Educação dos Arquitetos (UNESCO/UIA, 2011, p. 11): 
Além de todos os aspectos estéticos, técnicos e financeiros, das responsabilidades profissionais, as principais preocupações, expressas pela Carta, são relacionadas com o compromisso social da profissão, ou seja, a consciência do papel e da responsabilidade do arquiteto em sua respectiva sociedade, bem como a melhoria da qualidade de vida através de assentamentos humanos sustentáveis.

Atualmente existe uma grande preocupação, mesmo que ainda insuficiente, em evidenciar e acima de tudo formar profissionais arquitetos e urbanistas com uma visão complexa para a melhoria da qualidade de vida dos seres humanos. Repensar a atuação desse profissional de forma a compreender a sociedade como um todo, é de suma importância para a formação de profissionais reflexivos, colaborativos e criativos que visem o desenvolvimento de uma sociedade melhor e mais justa.

Para a Carta a atuação do arquiteto é muito clara e um dos seus objetivos é na melhoria da formação teórica e prática dos futuros arquitetos (UNESCO/UIA, 2011, p. 6).

\begin{abstract}
Nós, arquitetos, envolvidos com a evolução da qualidade do ambiente construído em um mundo em rápida mudança, acreditamos que tudo que tenha um impacto sobre a maneira em que o ambiente construído é planejado, projetado, fabricado, usado, equipado, configurado e mantido, pertence ao domínio da arquitetura. Nós nos sentimos responsáveis pela melhoria da formação teórica e prática dos futuros arquitetos de forma a lhes permitir responder às expectativas das sociedades do século XXI, em todo o mundo, sobre assentamentos humanos sustentáveis em cada contexto cultural.
\end{abstract}

No Brasil seria importante que os arquitetos e urbanistas repensassem sua atuação profissional. Algumas áreas de atuação dos arquitetos começam a ficar saturadas e outras estão esquecidas. Áreas de grande importância como as habitações sociais e o saneamento básico adequado para as classes média baixa e baixa são pouco interessantes para a maioria dos profissionais arquitetos e urbanista recém-formados. Devido á questão de mercado e de "status" profissional, muitos profissionais visam apenas desenvolver projetos em áreas com focos mais elitizados e que teoricamente se tem um melhor retorno financeiro. Entretanto isso deve ser repensado, principalmente pela necessidade social do país, pela grande quantidade de formação de profissionais arquitetos e pelo declínio do "boom" imobiliário. De acordo com a Carta (UNESCO/UIA, 2011, p. 12):

Há ainda oportunidades para desenvolver novas tarefas para a profissão, na medida em que os arquitetos se conscientizarem de necessidades identificadas de crescimento e oportunidades oferecidas em áreas que não têm sido, até agora, uma preocupação importante para a nossa profissão. Portanto, é necessária uma maior diversidade no exercício da profissão e, como consequência, na formação teórica e prática dos arquitetos. $\mathrm{O}$ objetivo fundamental da educação é formar o arquiteto como um "generalista".

Segundo o censo demográfico - IBGE de 2010, no Brasil 84,4 \% da população se encontra na área urbana, já na região sudeste esta porcentagem sobe para 93\%. Com relação aos domicílios particulares permanentes considerando o tipo de saneamento (distribuição 
percentual), no Brasil 38,2\% estão inadequados ou semi-adequados e no norte do país esta porcentagem chega a 77,6\% de domicílios com saneamento inadequado ou semi-adequado.

É importante salientar que para o levantamento do CENSO se considera saneamento adequado quando o domicílio está abastecido com água por rede geral, esgotamento sanitário por rede geral ou fossa séptica e lixo coletado diretamente ou indiretamente. Como saneamento semi-adequado quando pelo menos uma forma de saneamento considerada adequado e saneamento inadequado quando todas as formas de saneamento são consideradas inadequadas.

Existe uma grande demanda por trabalhos arquitetônicos e urbanísticos para a sociedade brasileira menos abastadas. Os educadores arquitetos e urbanistas devem repensar sobre o que ensinam, exigem, direcionam e estimulam em sala de aula. É importante salientar que não se deve ser contra a áreas consideradas mais nobres da arquitetura e urbanismo, entretanto é importante formar um profissional complexo que saiba analisar e compreender as questões do seu entorno e não só aquelas que mais lhe é financeiramente viável ou que o mercado está solicitando.

As futuras oportunidades para a profissão estarão na população menos abastada. Segundo a Carta UNESCO/UIA (2011, p. 12)

\footnotetext{
Isso se aplica particularmente para aqueles que trabalham no contexto dos países em desenvolvimento, onde os arquitetos podem aceitar o papel de "facilitador" ao invés de "provedor" e onde a profissão pode ainda enfrentar novos desafios. Não há dúvida de que a capacidade dos arquitetos para resolver problemas pode contribuir muito para tarefas relacionadas ao desenvolvimento comunitário programas autofinanciados, equipamentos educacionais, etc. e, assim, garantir uma contribuição significativa para a melhoria da qualidade de vida daqueles que não exercem seus plenos direitos de cidadãos e que não estão entre os clientes tradicionais dos arquitetos.
}

Verifica-se certa dificuldade na implantação de ações para o desenvolvimento da capacidade de arquitetos e urbanistas em resolver problemas principalmente devido à forma ultrapassada de pensar sobre o ensino e aprendizagem de docente e discentes. A origem desta dificuldade está no fato de que, desde a infância, o homem é ensinado e aprende que os pensamentos e as ideias deveriam ser conduzidos exclusivamente pela razão, organização e através das análises da simplificação e não da complexidade. Essa forma de organizar e direcionar o pensamento tem razões históricas e remonta à Revolução Iluminista do século XVII, reconhecido como o século do racionalismo.

Se o Brasil, com sua grande área territorial e sua diversidade sociocultural, mantiver o pensar simplificador e não estimular o pensamento complexo, a partir de novas estratégias de ensino e aprendizagem visando a formação de profissionais reflexivo, criativos e colaborativo, 
entendendo os problemas locais a partir de uma visão global, corre-se o risco de se estagnar como nação. Para a Carta UNESCO/UIA (2011, p. 11):

Os educadores devem preparar os arquitetos para desenvolver novas soluções para o presente e para o futuro, porque o novo tempo vai trazer com ele importantes e complexos desafios devido à degradação social e funcional em muitos assentamentos humanos. Estes desafios incluem urbanização global e um consequente esgotamento em ambientes já existentes, uma grave escassez de habitação, serviços urbanos e infraestrutura social, e a crescente exclusão de arquitetos em projetos relacionados com o ambiente construído.

Segundo a Carta (UNESCO/UIA, 2011, p. 14) a relação com o entorno e sua complexidade devem ser evidenciados, e que a arquitetura, a qualidade das construções e sua integração harmoniosa no seu ambiente circundante, o respeito pelas paisagens naturais e urbanas, bem como o patrimônio cultural coletivo e individual são questões de interesse público; e que é de interesse público, assegurar que os arquitetos sejam capazes de compreender as características regionais e traduzir as necessidades, expectativas e melhoramentos para a qualidade de vida dos indivíduos, grupos sociais, comunidades e assentamentos humanos.

Que os métodos de formação e aprendizagem para os arquitetos sejam diversificados, de forma a desenvolver uma riqueza cultural e permitir a flexibilidade no desenvolvimento dos programas de ensino para atender às mudanças nas demandas e nos requisitos do cliente, dos usuários, da profissão de arquiteto e da indústria da construção, mantendo-se atenção sobre as motivações políticas e financeiras por trás de tais mudanças.

O profissional reflexivo, criativo e colaborativo é de suma importância para uma visão melhor de mundo futuro. Segundo a carta esta visão do mundo futuro, transmitida nas escolas de arquitetura, deve incluir as seguintes metas (UNESCO/UIA, 2011, p. 11):

- Uma qualidade de vida decente para todos os habitantes dos assentamentos humanos.

- Uma aplicação tecnológica que respeite as necessidades sociais, culturais e estéticas dos homens com um conhecimento do uso adequado dos materiais na arquitetura, bem como seus custos iniciais e de manutenção.

- Um desenvolvimento ecologicamente equilibrado e sustentável do ambiente construído e natural, incluindo o aproveitamento racional dos recursos disponíveis.

- Uma arquitetura que é valorizada como sendo de propriedade e de responsabilidade de todos.

É importante salientar que para a formação de profissionais reflexivos é necessário primeiramente a formação de professores reflexivos. Para Ruaro (2004) em termos de sala de aula, a ação do professor se revela como teoria e prática. Teoria na medida em que ele é capaz de arranjar seus conhecimentos e traduzi-los em força de ação no cotidiano da sala, e enquanto ensina, não apenas transmite conhecimentos prontos, mas é capaz de provocar a construção e reconstrução de ideias e ações que possam modificar, não só o pensamento, mas via de consequência, a ação social, tornando-se assim uma educação transformadora. 
Ruaro ainda coloca que para poder transformar a realidade é preciso que o processo de transformação do professor, que vai atuar na sociedade, a qual deverá sofrer a transformação seja uma transformação teórico-prática que provoque a reflexão da mudança que se espera da ação desenvolvida por ele na sala de aula. Dessa forma, formar professores reflexivos exige mais do que ensinar a pensar, exige um pensar complexamente.

\section{Para a Carta -UNESCO/UIA (2011, p. 12):}

Que a formação em arquitetura desenvolve a capacidade nos alunos para conceber, projetar, entender e realizar o ato de construção, no contexto da prática da arquitetura que equilibra as tensões entre a emoção, a razão e a intuição dando forma física às necessidades da sociedade e do indivíduo. [...] Que a arquitetura é uma disciplina que usa conhecimentos de ciências humanas, ciências sociais e naturais, tecnologia, ciências ambientais, artes e humanidades.

Para o desenvolvimento da reflexão na formação de arquitetos e urbanistas, é necessário inicialmente a formação de professores que tenham claro a concepção de reflexão, este é o ponto chave da mudança educacional.

Muitos autores estabelecem três níveis diferentes de reflexão: Técnica, prática e crítica. Para Garcia (1992, p. 32):

O primeiro nível corresponde à análise das ações explícitas: o que fazemos é passível de ser observado (andar na sala de aula, fazer perguntas, motivar, etc.). O segundo nível implica o pensamento e a reflexão: planejamento do que vai fazer, reflexão sobre o que foi feito, destacando seu caráter didactico. Por último o nível das considerações éticas, que passam pela análise ética ou política da própria prática, bem como pelas repercussões contextuais; este nível de reflexão é imprescindível para o desenvolvimento de uma consciência crítica nos professores sobre suas possibilidades de acção e as limitações de ordem social e ideológica do sistema educativo.

Segundo a Carta UNESCO/UIA (2011) devem ser criados sistemas de educação continuada para os arquitetos, pois a educação em arquitetura nunca deve ser considerada como um processo concluído, mas como um processo que deve continuar ao longo da vida e que se deve transformar a mentalidade arquitetônica dos profissionais de forma que o método de criação seja uma parte de um processo cultural contínuo e harmonioso. Para que isso ocorra uma das estratégias é a formação em técnicas de pesquisa como parte integrante da educação em arquitetura, tanto para estudantes quanto professores.

Que a pesquisa e publicação devem ser consideradas como atividades inerentes aos educadores de arquitetura e devem abranger métodos aplicados e experiências no exercício profissional da arquitetura, na prática do projeto e nos métodos de construtivos, bem como nas disciplinas teóricas.

Para a carta UNESCO/UIA (2011) a formação do arquiteto envolve a aquisição das seguintes capacitações:

- Capacidade de ser criativo, inovar e assegurar a liderança da concepção.

- Capacidade de reunir informações, identificar problemas, aplicar análise e julgamento crítico, bem como formular estratégias de ação. 
- Capacidade de pensar tridimensionalmente na busca de uma concepção.

- Capacidade de conciliar fatores divergentes, integrar conhecimentos e usar essas competências na criação de uma solução de projeto.

A formação de arquitetos e urbanistas reflexivos, criativos, colaborativos e que compreendam as complexidades do mundo contemporâneo necessita das seguintes habilidades:

- Capacidade de trabalhar em colaboração com outros arquitetos e membros de equipes interdisciplinares.

- Capacidade de agir e de comunicar ideias através da colaboração, falando, calculando, escrevendo, desenhando, modelando e avaliando.

- Capacidade de utilizar habilidades manuais, eletrônicas, gráficas e de modelagem para explorar, desenvolver, definir e comunicar uma proposta de projeto.

- Compreensão dos sistemas de avaliação, que utilizam meios manuais e / ou eletrônicos para as avaliações de desempenho dos ambientes construídos.

Além das competências e habilidades acima, a Carta (UNESCO/UIA, 2011) sugere que além dos cinco anos de estudo, aos graduados em arquitetura será exigido concluir ao menos dois anos (ainda que o recomendável seja três) de experiência prática/treinamento/estágio, antes do registro/licença/certificação para a prática como um profissional arquiteto. Com alguma flexibilidade para fins de equivalência, é aceitável que desse total, um ano de prática possa ser obtido antes da conclusão dos estudos acadêmicos.

Como se pode verificar, a questão da teoria e da prática é uma questão singular na formação de profissionais arquitetos e urbanistas reflexivos, criativos e colaborativos.

Para Demo (2011) uma possibilidade para a formação de profissionais reflexivos está no currículo intensivo em educar pela pesquisa.

O currículo intensivo representa proposta de organização alternativa da didática acadêmica (universitária ou de educação superior) tendo em vista o perfil do cidadão e do profissional moderno, de quem se espera competência questionadora reconstrutiva, não a simples reprodução de saberes e fazeres. Incorpora precisamente o desafio de educar pela pesquisa.

A pesquisa não pode estar afastada do ato de educar. Afastando-se da pesquisa a universidade joga fora a chance de colocar-se como centro do desenvolvimento humano e manter-se como instrumento para a reconstrução do conhecimento inovador, da ética e da reflexão. 
Segundo Demo (2011, p.112) a dificuldade em relacionar pesquisa com o compromisso educativo encontra-se em três níveis: Professor, Aluno e Pesquisador.

Primeiro, mesmo no professor, pesquisa é coisa peregrina, ainda que cresça a pressão sobre a necessidade de pesquisar, à medida que se exige pós-graduação, sem falar que faz parte da trilogia obscura e piedosa "ensino, pesquisa e extensão". Sobretudo entidades particulares e mais ainda aquelas que funcionam apenas a noite, contratam como professores pessoas que veem imbuídas da tarefa de 'dar aula', e nada fazem além disso, não só porque não tem tempo ou motivação, mas principalmente porque lhes é estranho ou inviável. Todavia, também em entidades públicas e mesmo em universidades federais, há uma maioria de professores que só dão aula, ou apenas ensinam a copiar.

Segundo, pesquisar, no aluno, é tido como pretensão descabida e mesmo equivocada, servindo para tanto as alegações mais variadas e esdrúxulas, como uma má preparação na educação básica, seu desinteresse, alimentado ademais pela necessidade de trabalhar durante o dia, sua incompatibilidade porque a profissão não exigiria pesquisa, a precariedade do ambiente, destituído, por exemplo, de biblioteca, dados, tempo curricular, etc. Com isto, é condenado a escutar aulas copiadas, tomar notas e fazer prova.

Terceiro, o pesquisador, por sua vez, também ignora comumente sua importância educativa, porque se vê como produtor de conhecimento, cercado de questões metodológicas, teóricas, empíricas, práticas, terminando sua tarefa na conclusão do relatório de pesquisa. Geralmente entende-se como professor especial, tão especial que não quer mais o contato com os alunos, e passa a formar uma espécie de elite acadêmica, compensada muitas vezes por apoios financeiros específicos, contatos nacionais e internacionais instigantes, prestígio e ocupação de espaços. Não lhe ocorre ser educador.

Nesse contexto é fundamental desenvolver ações que apoiem estratégias de 'educar pela pesquisa' tanto para discentes quanto para docentes. Para Demo (2011) a pesquisa não pode ser afastada do ato de educar e nesse sentido faz-se necessário compreender como o ato de desenvolver pesquisa e a questão ética se relaciona com os seus principais atores: Universidades, docentes, discentes e órgãos de fomento da pesquisa. Afastando docentes e discentes da pesquisa, a universidade joga fora a chance de colocar-se como centro do desenvolvimento humano e manter-se como instrumento para a reconstrução do conhecimento inovador, da ética e da reflexão.

Como relação as estratégias que estão sendo tomadas para a compreensão da importância da questão ética no desenvolvimento da pesquisa no Brasil podemos verificar a constituição de algumas comissões e códigos de condutas éticas que deram início a discussão.

Criada por meio da Resolução 196/96 e com constituição designada pela Resolução 246/97, a Comissão Nacional de Ética em Pesquisa - CONEP- é uma comissão do Conselho Nacional de Saúde - CNS e tem principal objetivo implementar as normas e diretrizes regulamentadoras de pesquisas envolvendo seres humanos. É importante salientar que esta comissão além de consultiva, deliberativa e normativa tem, também a função educativa, atuando conjuntamente com uma rede de Comitês de Ética em Pesquisa - CEP pertencentes as instituições onde são realizadas as pesquisas. Conforme descrito no site do Conselho Nacional de Saúde - CNS (2015, p. 2) 
A CONEP deverá examinar os aspectos éticos de pesquisas envolvendo seres humanos em áreas temáticas especiais, encaminhadas pelos CEP das instituições, e está trabalhando principalmente na elaboração de normas específicas para essas áreas, dentre elas, genética humana, reprodução humana, novos dispositivos para a saúde, pesquisas em populações indígenas, pesquisas conduzidas do exterior e aquelas que envolvam aspectos de biossegurança. Está organizando um sistema de acompanhamento das pesquisas realizadas no país.

O CEP institucional deverá revisar todos os protocolos de pesquisa envolvendo seres humanos, cabendo-lhe a responsabilidade primária pelas decisões sobre a ética da pesquisa a ser desenvolvida na instituição, de modo a garantir e resguardar a integridade e os direitos dos voluntários participantes nas referidas pesquisas. Terá também papel consultivo e educativo, fomentando a reflexão em torno da ética na ciência, bem como a atribuição de receber denúncias e requerer a sua apuração.

É importante destacar que tanto a Comissão Nacional de Ética em Pesquisa - CONEP quanto o Comitês de Ética em Pesquisa - CEP são formados com base numa visão multidisciplinar, tendo a participação de pesquisadores, estudiosos de bioética, juristas, profissionais de saúde, das ciências sociais, humanas e exatas e representantes de usuários.

Como forma de sistematizar e registrar pesquisas envolvendo seres humanos para o CEP/CONEP foi consolidada em 2012 uma base nacional e unificada de registros denominada de Plataforma Brasil ${ }^{4}$ que permite que as pesquisas sejam acompanhadas em seus diferentes estágios - desde sua submissão até a aprovação final pelo CEP e pela CONEP.

Esta preocupação com a questão da ética na pesquisa também é preocupação dos órgãos de fomento no Brasil. No caso da Fundação de Amparo a Pesquisa do Estado de São Paulo - FAPESP as questões éticas no desenvolvimento das pesquisas científicas por ela fomentadas estão apresentadas em seu site na forma de uma Código de Boas Práticas Científicas.

No curso das últimas décadas, consolidou-se internacionalmente o consenso de que as questões relativas à integridade ética das atividades científicas devem merecer, da comunidade científica e das instituições por meio das quais ela se organiza, atenção contínua e sistemática. Consolidou-se também o consenso de que elas devem ser objeto de autorregulação por essa comunidade. Assim, especialmente nos últimos dez anos, em várias partes do mundo, vêm sendo formuladas, por meio de regulamentos e códigos de conduta, políticas institucionais para o tratamento dessas questões e vêm sendo criados órgãos institucionais encarregados de sua implementação (FAPESP, 2014, p. 9).

No Código de Boas Práticas Científicas encaminhada pela Diretoria Científica ao Conselho Superior da FAPESP - Fundação de Amparo a Pesquisa do Estado de São Paulo, verifica-se que:

Além dos preceitos éticos a que todas as pessoas estão submetidas, independentemente da singularidade de suas atividades profissionais, aplicam-se também ao cientista normas de conduta que derivam da finalidade específica de sua profissão: a construção e a apropriação coletivas da ciência. Essas normas definem a integridade ética das atividades científicas e

\footnotetext{
${ }^{4}$ Desde janeiro de 2012, para o registro de pesquisas envolvendo seres humanos, a Plataforma Brasil substituiu o SISNEP - Sistema Nacional de Ética em Pesquisa. (www.saude.gov.br/plataformabrasil).
} 
podem ser deduzidas de um princípio fundamental: todo cientista deve exercer sua profissão da maneira mais apropriada para que daí resulte a melhor contribuição para o avanço da ciência (FAPESP, 2014, p. 9).

No Código de Conduta de Boas Práticas da Fapesp um ponto de grande importância para a abordagem desse artigo está sobre a responsabilidade das Universidades/ Instituições de Pesquisa. Segundo o Código de boas práticas científicas - FAPESP (2014, p. 35-36):

As instituições de pesquisa compartilham com os pesquisadores individuais a responsabilidade pela preservação da integridade ética da pesquisa científica. Elas são as responsáveis principais pela promoção de uma cultura de boa conduta científica entre os pesquisadores e estudantes a ela vinculados, assim como pela prevenção, investigação e punição de más condutas científicas que ocorram em seu âmbito.

- Toda instituição de pesquisa deve ter políticas e procedimentos claramente formulados para lidar com a questão da integridade ética da pesquisa.

- Toda instituição que se apresente perante a FAPESP como sede de atividades de pesquisa deve incluir, em seu organograma, um ou mais órgãos especificamente encarregados de: (a) promover a cultura da integridade ética da pesquisa, mediante programas regulares de educação, disseminação, aconselhamento e treinamento acessíveis a todos os pesquisadores a ela vinculados; (b) investigar e, se for o caso, punir a ocorrência de possíveis más condutas científicas e reparar os prejuízos científicos que tenham causado.

- Todo periódico científico deve prever a utilização regular de proce- dimentos de identificação de más condutas científicas durante os pro- cessos de avaliação de trabalhos científicos que lhe sejam submetidos para publicação. Essa utilização regular será considerada pela FAPESP como item importante na avaliação de pedidos de Auxílio à Publicação que lhe sejam encaminhados. Uma vez identificada a ocorrência de má conduta científica relacionada a pesquisa apoiada pela FAPESP, os edi- tores do periódico devem imediatamente informá-la às instituições de pesquisa dos autores do trabalho científico em causa e à FAPESP.

- Quando estabelecida a ocorrência de má conduta científica que possa ter afetado o valor científico de um trabalho já publicado em um periódico, este deve divulgar clara e expressamente o fato em seu nú- mero imediatamente seguinte.

A formalização da responsabilidade das Universidades/ Instituições de pesquisa é de suma importância para o entendimento da questão ética na pesquisa brasileira, assim auxiliando docentes e discentes no desenvolvimento de ensino aprendizagem éticos com base no educar pela pesquisa. Segundo Santos (2011) no artigo intitulado: Sobre a integridade ética da pesquisa, as Instituições de pesquisa tem a responsabilidade de garantir a ética na pesquisa que é desenvolvida sob seu domínio.

É um consenso que, no plano institucional, as instituições de pesquisa têm a responsabilidade principal por garantir que as pesquisas que nelas se realizam se conformem aos padrões da integridade ética da pesquisa. Por ser o ambiente próximo em que os pesquisadores desenvolvem sua atividade científica, ela dispõe dos meios mais ágeis e eficazes para promover entre seus pesquisadores os valores da ética da pesquisa, e também para implementar mecanismos de prevenção, identificação, investigação e punição de eventuais más condutas (SANTOS, 2011, p. 54)

Os órgãos de fomento da pesquisa no Brasil começam a evidenciar a importância da integridade ética na pesquisa.

Como pode-se observar, exercitar os docentes e discentes no Brasil por meio do 'educar pela pesquisa' é de suma importância para o desenvolvimento de um país socialmente 
mais responsável, entretanto, quando se aborda a questões sobre a ética na educação e na pesquisa brasileira, principalmente sobre o ensino de arquitetura e urbanismo no Brasil, verifica-se um abismo entre o existente e o ideal.

Para estimular a formação de profissionais reflexivos, criativos e colaborativos, precisa-se anteriormente contribuir com a melhoria da formação dos professores. Sem professores reflexivos, criativos e colaborativos como formar profissionais com estas competências?

Investir na qualificação do professor não deve ser entendida pelas Instituições de Ensino Superior como item positivo apenas para as avaliações dos cursos e da IES pelo Ministério da Educação. Entender o professor como peça fundamental para a formação de profissionais reflexivos, criativos e colaborativos é fundamental para o desenvolvimento social e ético do Brasil.

Estimular a contínua qualificação, a pesquisa e acima de tudo valorizar o professor é um dos caminhos para ter êxito na formação de um arquiteto e urbanista com compromissos sociais e éticos.

\section{Considerações finais}

Possibilitar a formação de profissionais reflexivos, criativos e colaborativos é de grande importância para o desenvolvimento social, contudo, para que isso seja verdadeiramente aplicado, é preciso uma reestruturação na forma de ensinar e de aprender. Esta nova forma de ensinar e aprender, visando a reflexão, a criação e a colaboração dentro de uma sociedade que vivencia os constantes avanços das tecnologias comunicacionais e informacionais, deve ser entendida, como uma necessidade de mudança a curto e médio prazo.

As mudanças devem ser encaradas de modo positivo, por discentes, docentes, na forma de aprender/ ensinar, e principalmente pelos gestores institucionais na forma de gerir e direcionar esta nova forma de educação dentro do Plano de Desenvolvimento Institucional, do Projeto Pedagógico Institucional e do Projeto Pedagógico de Curso, envolvendo as diversas instâncias institucionais focadas na formação de profissionais reflexivo, criativos e colaborativo.

A mudança não pode vir apenas de um lado, mas sim do afinamento de todos os atores pertencentes à Instituição de Ensino Superior, com a finalidade de retomar o verdadeiro objetivo da Universidade, que é universalizar o conhecimento. 
Universalizar o conhecimento está diretamente interligado na relação pesquisa e ensino. A pesquisa não pode estar afastada do ato de educar. Afastando-se da pesquisa a universidade joga fora a chance de colocar-se como centro do desenvolvimento humano e manter-se como instrumento para a reconstrução do conhecimento inovador, da ética e da reflexão.

Essa preocupação em aproximar aluno e profissional de arquitetura e urbanismo ao ensino e pesquisa, já começa a ser evidenciado em alguns projetos pedagógicos no Brasil.

$\mathrm{Na}$ matriz curricular do curso de Arquitetura e Urbanismo do curso do Instituto Federal Fluminense, encontra-se duas disciplinas optativas que evidenciam a preocupação com o ensino, pesquisa e com a formação de profissionais reflexivos, criativos e colaborativos; e seu compromisso social.

Uma das disciplinas denominada de Docência Superior tem como objetivo analisar e refletir sobre:

- As teorias pedagógicas: o ato de ensinar e aprender; como ensinar; como os alunos aprendem; o Ensino Superior, com ênfase no curso de Arquitetura e Urbanismo e o perfil do aluno.

- Modelos de Ensino, as competências do professor do Ensino Superior. O compromisso social do educador.

- Prática em docência superior presencial e a distância. Aulas práticas com acompanhamento de técnico-pedagógico.

- Plataforma Moodle com instrumento no ensino a distância.

- Atuação pedagógica reflexiva e transformativa na formação de profissionais de arquitetura e urbanismo e de homens comprometidos com o desenvolvimento humano.

Com esta disciplina se verifica a preocupação dos gestores do curso/IES com o ensino e aprendizagem na formação de arquitetos e urbanistas e principalmente com a formação de alunos reflexivos que podem se tornar futuros professores reflexivos.

Analisar e refletir sobre as atuais teorias pedagógicas, modelos de ensino, evidenciando o compromisso social do educador e de seu comprometimento com o desenvolvimento humano é de suma importância para o desenvolvimento do ensino/aprendizado de Arquitetura e Urbanismo no Brasil.

\section{Referências}

BOURDIEU, Pierre. Homo academicus. Florianópolis: UFSC, 1984. 
CELAM. Conselho Episcopal Latino-Americano. Conclusões de Medellin sobre educação. Rio de Janeiro: AEC do Brasil, 1978.

CSN - Conselho Nacional de Saúde. Disponível em:

<http://conselho.saude.gov.br/comissao/conep/atribuicoes.html> Acesso em: 20 nov. 2015.

CORBISIER, Roland. Formação e problema da cultura brasileira. 3. ed. Rio de Janeiro: ISEB, 1960.

DEMO, Pedro. Educação pela pesquisa. Campinas: Autores Associados, 2011.

DIAS, Rafael; SERAFIM, Milena. Comentários sobre as transformações recentes na universidade pública brasileira. Avaliação, Campinas; Sorocaba, v. 20, n. 2, p. 335-351, 2015.

FAPESP - Fundação de Amparo a Pesquisa do Estado de São Paulo. Código de boas práticas científicas. 2014. Disponível em: < http://www.fapesp.br/boaspraticas/FAPESPCodigo_de_Boas_Praticas_Cientificas_2014.pdf>. Acesso em: 11 nov. 2015.

FERNANDES, Florestan. A sociologia numa era de revolução social. 2. ed. Rio de Janeiro: Zahar, 1976.

FERREIRA, Cláudio Lima. O ensino de arquitetura e urbanismo no Brasil: formando profissionais reflexivos, criativos e colaborativos. Alemanha: Novas Edições Acadêmicas, 2016.

GARCIA, Carlos Marcelo. A formação de professores: novas perspectivas baseadas na investigação sobre o pensamento do professor. In: NÓVOA, A. Os professores e sua formação. Lisboa: Publicações Dom Quixote, 1992. p. 51-76.

LUCKESI Cipriano et al. Fazer universidade: uma proposta metodológica. São Paulo: Cortez, 2001.

PAPA FRANCISCO. Entrevista dada em 25 de junho de 2013, na Jornada Mundial da Juventude. Rio de Janeiro. Disponível em: <http://g1.globo.com/jornada-mundial-dajuventude/2013/noticia/2013/07/papa-fala-de-corrupcao-e-diz-jovens-para-nao-seacostumarem-ao-mal.html>. Acesso em: 25 set. 2013.

RIBEIRO, Darcy. A universidade necessária. Rio de Janeiro: Paz e Terra, 1975.

RUARO, Dirceu António. Prática reflexiva de professores: possibilidades e limites. Pato Branco: Imprepel, 2004.

SANTOS, Luiz Henrique Lopes dos. Sobre a integridade ética da pesquisa. São Paulo: FAPESP, 2011. Disponível em: 〈http://www.fapesp.br/6566>. Acesso em: 3 out. 2013.

SERAFIM, Milena Pavan. O processo de mercantilização das instituições de educação superior: um panorama do debate nos EUA, na Europa e na América Latina. Avaliação, Campinas; Sorocaba, v. 16, n. 2, p. 241-265, 2011.

SGUISSARDI, Valdemar. Universidade pública estatal: entre o público e o privado/mercantil. Educação e Sociedade, Campinas, v. 26, n. 90, p. 191-222, jan./abr. 2005.

TEIXEIRA, Anísio. Educação no Brasil. São Paulo: Companhia Editora Nacional, 1969.

UNESCO/UIA. Carta para a educação dos arquitetos. 2011. Disponível em: <http://www.abea-arq.org.br/wp-content/uploads/2013/03/Carta-UNESCO-UIA-2011.pdf>. Acesso em: 3 out. 2013. 
A formação de um arquiteto social e ético: dilemas das universidades brasileiras

${ }^{1}$ Cláudio Lima Ferreira Universidade Estadual de Campinas | Instituto de Artes Campinas | SP | Brasil. Contato: limacf@g.unicamp.br ORCID (iD) https://orcid.org/0000-0001-8345-5091

${ }^{2}$ Wilson Flório Universidade Presbiteriana Mackenzie | PPG Arquitetura e Urbanismo Campinas | SP | Brasil. Contato: wflorio@uol.com.br ORCID (iD) https://orcid.org/0000-0002-6940-8341

Artigo recebido em 24 de novembro de 2015 e aprovado em 10 de setembro de 2018. 